\title{
Retraction Note: Dietary patterns and their associations with socio-demographic and lifestyle factors in Tasmanian older adults: a longitudinal cohort study
}

\author{
Hoa H. Nguyen (1) - Feitong Wu (1) - Wendy H. Oddy • Karen Wills • Sharon L. Brennan-Olsen • Graeme Jones • \\ Tania Winzenberg
}

Published online: 5 December 2019

(c) Springer Nature Limited 2019. This article is published with open access

\section{Retraction Note to: \\ European Journal of Clinical Nutrition (2019) 73:714-723 https://doi.org/10.1038/s41430-018-0264-1}

The authors have retracted this article [1] after discovering a major error in the data analysis made when generating the grouped items used in the factor analysis generating the dietary patterns. Because the error is in the foundations of the analysis, it means that the dietary patterns identified were themselves erroneous and their associations with socio-demographic factors are also incorrect. A re-analysis showed up major differences in outcomes when compared with those in [1]. The authors have been given the opportunity to submit a new manuscript for peer review. All authors agree with this retraction.

[1] Hoa H. Nguyen, Feitong Wu, Wendy H. Oddy, Karen Wills, Sharon L. Brennan-Olsen, Graeme Jones \& Tania
Winzenberg. Dietary patterns and their associations with socio-demographic and lifestyle factors in Tasmanian older adults: a longitudinal cohort study. 2019;73:714-723.

Open Access This article is licensed under a Creative Commons Attribution 4.0 International License, which permits use, sharing, adaptation, distribution and reproduction in any medium or format, as long as you give appropriate credit to the original author(s) and the source, provide a link to the Creative Commons license, and indicate if changes were made. The images or other third party material in this article are included in the article's Creative Commons license, unless indicated otherwise in a credit line to the material. If material is not included in the article's Creative Commons license and your intended use is not permitted by statutory regulation or exceeds the permitted use, you will need to obtain permission directly from the copyright holder. To view a copy of this license, visit http://creativecommons. org/licenses/by/4.0/. 